\title{
Tolerance of canola to drought and salinity stresses in terms of root water uptake model parameters
}

\author{
Aki Yanagawa ${ }^{1}$, Haruyuki Fujimaki ${ }^{2}$ \\ ${ }^{1}$ Department of Mechanical and Environmental Informatics, Tokyo Institute of Technology, 2-12-1-W8-4 O-okayama, Meguro-ku, \\ Tokyo, 152-8552, Japan. \\ ${ }^{2}$ The National University Corporation Arid Land Research Center, Tottori University, 1390 Hamasaka, Tottori, 680-0001, Japan. \\ *Corresponding author. Tel: +81-3-5734-2190. E-mail: akihoshi0619@gmail.com
}

\begin{abstract}
Canola (Brassica napus) is cultivated for oil as a biofuel crop. Few quantitative data concerning its tolerance to abiotic stresses has been presented. We evaluated the tolerances of canola to drought and salinity stresses in terms of parameter values in a macroscopic root water uptake model. We conducted an experiment using nine columns with two plants in each: three columns were under drought stresses, another three were under saline stress and others provided potential transpiration. Two soil moisture and salinity probes were inserted into each of the six columns under stress to monitor water content and electrical conductivity. Weight of the columns was manually measured to obtain daily transpiration. Water uptake at each depth and time was calculated by substituting linearly interpolated matric and osmotic potentials into the stress response function. Determined stress response functions indicated that canola is more sensitive to drought compared to Jatropha. While, it was found to be as tolerant as Jatropha to salinity stress in terms of transpiration. Matric potential was more determining than osmotic potential to root water uptake of canola.
\end{abstract}

Keywords: Irrigation with saline water; Biofuel crops; Electrical conductivity; Feddes's model.

\section{INTRODUCTION}

Canola (Brassica napus) is the most popular variety of rapeseed and is widely cultivated as an oil crop in the world. Canola is also a candidate as a biofuel crop in arid and semi-arid regions. Drought and salinity stresses are the major limitations for plant growth in arid and semi-arid regions (Huzsvai and Rajkai, 2009). Previous studies noted greatly reduced canola yields due to high temperature and severe drought stress (Johnson et al., 1995). On the other hand, according to Nielsen (1997), canola yield is not significantly affected by water stress at any particular growth stage. There are different reports about the drought stress tolerance of canola. Regarding its tolerance to salinity stress, canola was found to have threshold values of soil salinity at about $10 \mathrm{dS} \mathrm{m}^{-1}$ for vegetative growth (Francois, 1994). Other studies also discussed salinity tolerance of canola and its cultivars (Ashraf and McNeilly, 1990; Huang and Redmann, 1995; Redmann et al., 1994). These previous studies presented quantitative data for its tolerance. A report of relationship between irrigation level and yield may be useful for certain conditions but may not be applicable to other combinations of soil, climate, and irrigation water salinity. Therefore, it is important to obtain universal indices of the plants stress tolerance, which do not depend on limited environmental conditions.

In arid and semi-arid regions, agricultural or municipal wastewater is often used for irrigation due to lack of irrigation water. Use of wastewater for biofuel production would be reasonable since municipal wastewater is generally not suitable for food production due to either potential health problems or psychological reasons, even after a second treatment. Biofuel crops are considered as proper crops in these areas. In these drier regions, drought and salinity stresses are caused by saline irrigation water, limited water supply or combination of those. Ahmadi and Ardekani (2006) showed parameter values for salinity stress tolerance of canola cultivars. Tolerances for both drought and salinity stresses should be obtained to optimize irrigation scheduling, to select proper crops in bio-energy pro- jects, and to predict long term yield trends under changing climate and as well as the to assess the impacts of its cultivation on the environments including the hydrological cycle if it is widely cultivated in a region. Since biomass production is proportional to transpiration amount, the capability of plant to keep up water uptake from soil and thus transpiring under stress is the essence of tolerance. Commonly obtained relationships between treatments and yields in field or laboratory experiments do not provide enough information on the dynamics of plant transpiration rate changes under given conditions. Therefore, root water uptake (RWU) models have been developed to predict plant response to irrigation and stresses (Feddes et al., 1978; Nimah and Hanks, 1973). Evaluation of tolerances of canola to drought and salinity stress in terms of parameter values in root water uptake models may help to understand and predict the net primary production in response to the quality and quantity of irrigation water. Macroscopic root water uptake models using stress response functions which are widely employed in user-friendly hydraulic simulation models of the soilatmosphere-plant system such as HYDRUS (Šimůnek et al., 2006; Twarakawi et al., 2010) and SWAP (Van Dam et al., 1997).

The purpose of this study was to determine tolerance-related parameter values in a widely used root water uptake model of canola. Then, the parameter values were compared with those of a major biofuel crop, Jatropha.

\section{THEORY}

In Feddes's model, the rate of water uptake, $S\left(\mathrm{~s}^{-1}\right)$, being a sink term in the continuity equation, which is calculated by multiplying the RWU reduction coefficient $\alpha$ by the potential water uptake rate $S_{p}\left(\mathrm{~s}^{-1}\right)$ (Feddes et al., 1978; Feddes and Raats, 2004):

$$
S=\alpha S_{p}
$$


Combined water and salinity stresses have been proposed in macroscopic RWU models (Feddes and Raats, 2004; Homaee et al., 2002). To express the reduction of the water uptake rate under the coexistence of drought and osmotic stresses, we employed an additive form:

$$
\alpha=\frac{1}{1+\left(\frac{h}{h_{50}}+\frac{h_{o}}{h_{o 50}}\right)^{p}},
$$

where $h$ and $h_{o}$ are the matric and osmotic heads, respectively, and $h_{50}, h_{050}$, and $p$ are fitting parameters (van Genuchten, 1987). Note that $h_{50}$ and $h_{050}$ are the respective matric and osmotic potentials when the water uptake is $50 \%$ of its potential rate. Those potentials therefore represent simple indices of the stress tolerance of the plants. The potential water uptake rate is proportional to both the normalized root density $\beta\left(\mathrm{cm}^{-1}\right)$ and the potential transpiration rate $T_{p}\left(\mathrm{~cm} \mathrm{~s}^{-1}\right)$ :

$S_{p}=\beta T_{p}$

The $\beta$ is obtained by dividing the root length density by the integral of root length density over the root zone:

$$
\beta=\frac{\rho_{r}}{\int \rho_{r} \mathrm{~d} z}
$$

where $\rho_{\mathrm{r}}$ is the density of active roots, often represented by root length density $\left(\mathrm{cm}^{-2}\right)$, and $z$ is the depth $(\mathrm{cm})$. Since transpiration rate $T_{c a l}$ is an integral of $S$ over the root zone, $T_{c a l}$ is calculated from

$$
T_{c a l}=\frac{T_{p}}{\int \rho_{r} \mathrm{~d} z} \int \alpha \rho_{r} \mathrm{~d} z
$$

\section{MATERIALS AND METHODS Experimental setup}

Nine columns (A, B, C, D, E, F, G, H and I) having $15 \mathrm{~cm}$ diameter and $20 \mathrm{~cm}$ height were placed in the growth chamber at University of Tsukuba in Japan. The material of the columns (Wagner pot) was white high impact polystyrene. Until March 11 th 2011 , the internal temperature was maintained at $24^{\circ} \mathrm{C}$ and day length was set to 14 hours. The columns were moved to a greenhouse on March 18th. The effects of uncontrolled climatic condition could be filtered out by using the reference columns. Columns $\mathrm{A}, \mathrm{B}$ and $\mathrm{C}$ were used for evaluating the tolerance to drought stress, D, E, and F for salinity stress and G, H and I provided potential transpiration. To monitor water content, bulk electrical conductivity (EC), and temperature in the soil at every hour, two dielectric moisture probes (5TE, Decagon Devices, Inc. Pullman, WA) were inserted horizontally into each of the six columns. The center rods (it is a three-rod sensor) were located at 5 and $15 \mathrm{~cm}$ depth, respectively as shown in Fig. 1. Air-dried Kanto loam soil (sand 50\%, silt 44\%) was packed into the columns to a bulk density of $0.82 \mathrm{~g} \mathrm{~cm}^{-3}$. Such a low bulk density even after light compaction is a remarkable character of the volcanic ash soil. To minimize non-uniformity during packing, the mass of every $5 \mathrm{~cm}$ of the packed soil was measured before the next soil increment was added. The soil surface was covered with white, $1 \mathrm{~cm}$ thick styrene foam to prevent evaporation, thus allowing only transpiration. Cottonfilled glass pipes ( $1 \mathrm{~cm}$ o.d. and $15 \mathrm{~cm}$ long) were placed at the bottom of each column to allow gravity drainage through a hole at the bottom of the column at the side (Fig. 1).

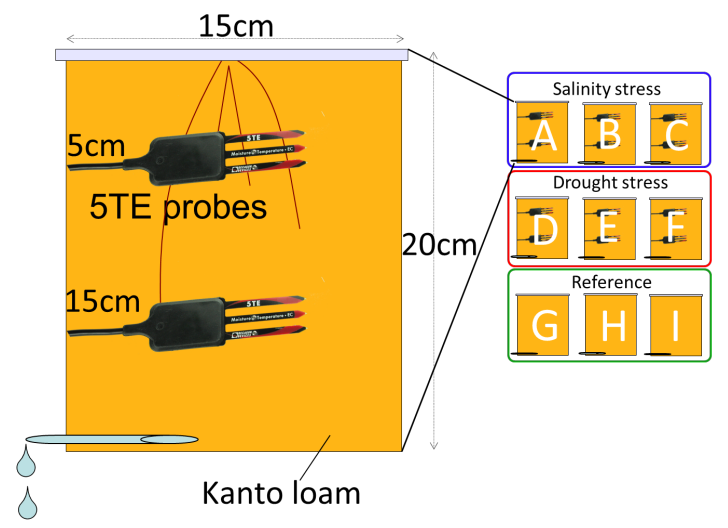

Fig. 1. Schematic illustration of the experimental setup. Two sensors to measure soil water content and electrical conductivity were inserted into column A, B, C, D, E and F.

\section{Experimental procedure}

Seeds of cultivated variety of canola (Brassica napus) obtained from Egypt were sown on 17th January, 2011, and each one was transplanted into the column on 9th February. Plants were thinned into two (pairs) for each column.

The stress period started after healthy plants had grown by applying sufficient amount of tap water $\left(\mathrm{EC}=0.6 \mathrm{~d} \mathrm{~S} \mathrm{~m}^{-1}\right)$ with 500 fold-diluted liquid fertilizer $(\mathrm{N}-\mathrm{P}-\mathrm{K}=6-10-5$, Hyponex Japan, Osaka, Japan). The last irrigation was performed on 2nd March, 2011 for the column A, B and C. The last irrigation with $\mathrm{NaCl}$ solution (4000 ppm) was performed on 10th March for the column D, E and F. We stopped applying tap water and $\mathrm{NaCl}$ solution completely during drought (from 2nd March) and salinity stress (from 10th March) periods. The other three columns $(\mathrm{G}, \mathrm{H}$ and $\mathrm{I})$ were used to provide potential transpiration by adding water lost by transpiration since the previous irrigation.

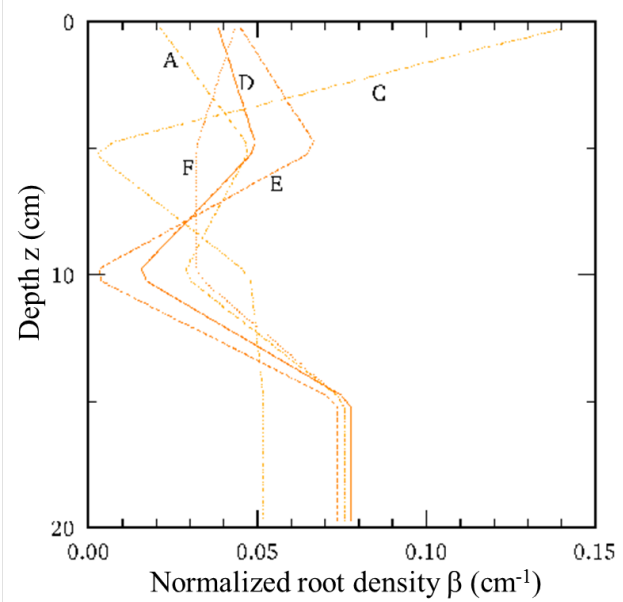

Fig. 2. Distribution of normalized root density for each column. Plants in column A-C and D-F were under drought and salinity stress, respectively. 


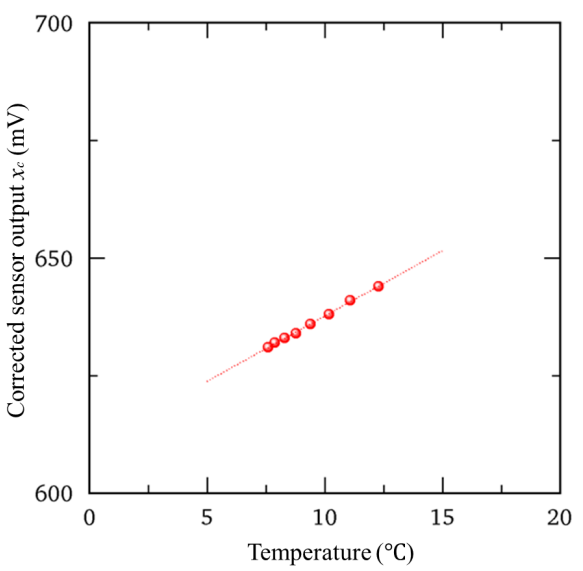

Fig. 3. Dependence of 5TE (Decagon Devices, Inc. Pullman, WA) sensor output on temperature.

The daily transpiration rate was measured by manually weighing the columns during lights-out (night) time of growth chamber. It was changed to the time of sunset after 11th March. We could not measure daily transpiration from 12th to 17th March due to a long power failure after the earthquake hit the Fukushima nuclear power plant. Potential transpiration was calculated by multiplying the mean value of potential transpiration rate of reference columns ( $\mathrm{G}, \mathrm{H}$ and $\mathrm{I})$ by a correction factor representing the differences in growth among the columns. The experiment was terminated (A, B, F: 30th March; C and D: 22nd March; E: 26th March) when the relative transpiration rate, the ratio of actual to potential transpiration, became about 0.5 . After the stress period, the columns were dismantled to obtain root length density distribution. Soil samples containing root at each $5-\mathrm{cm}$ layer were air-dried and sieved with a 2 $\mathrm{mm}$ screen. Then the air-dry roots were scanned with a flatbed scanner with 300 dpi. Total length of roots in an image was determined with the intersection method (Newman, 1966). Fig. 2 shows profiles of root length density. Malfunction of sensor response occurred at column $\mathrm{B}$ during the stress period. Thus, the parameter values for drought stress were determined based on the results from columns $\mathrm{A}$ and $\mathrm{C}$.

\section{Calibration}

To obtain accurate soil water content data using a moisture probe, we determined calibration functions for the soil. We first corrected the effect of individual difference as follow since we found that the probe has a relatively large variation with a coefficient of variation of 0.07 .

$x_{c}=a_{5 T E} x$,

where $x_{c}, a_{5 T E}$ and $x$ are corrected sensor output, correction factor for individual difference and raw sensor output, respectively. We also corrected the output to eliminate the effect of temperature (Fig. 3). Since the relationships were found to be linear, sensor output at reference temperature, $x_{r}$ was calculated by:

$x_{r}=x_{c}-a_{T}\left(T-T_{r}\right)$

where $a_{T}, T$ and $T_{r}$ are temperature coefficient, temperature (K) and reference temperature, respectively. We also found that the temperature coefficient linearly depends on sensor output as shown in Fig. 4. Temperature coefficient $\left(a_{T}\right)$ was thus calculated by:

$a_{T}=0.0072 x_{c}+2.1$

Then the output values corrected to the reference temperature were substituted into the following calibration function, which was determined using data at various salinity values ( $\mathrm{NaCl}$ solution of $0,2000,4000 \mathrm{ppm}$ ) of soil solution and volumetric water content, $\theta\left(\mathrm{cm}^{3} \mathrm{~cm}^{-3}\right)$ (Fig. 5).

$\theta=0.022 x_{r}^{0.5}-0.22$

Water content at each depth was estimated by interpolating or extrapolating measured values at the two depths. Matric head, $h$, at each depth was estimated using retention curve of the soil (Kanto loam) considering its hysteresis using a simple method of Kool and Parker (1987).

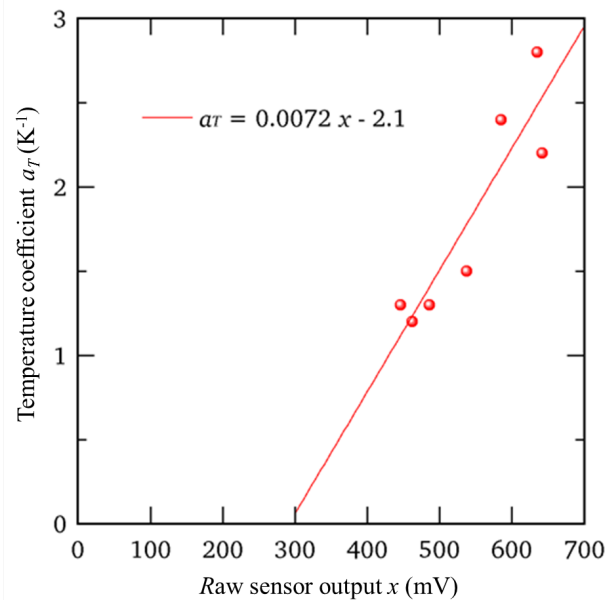

Fig. 4. Dependence of temperature coefficient on 5TE sensor outputs.

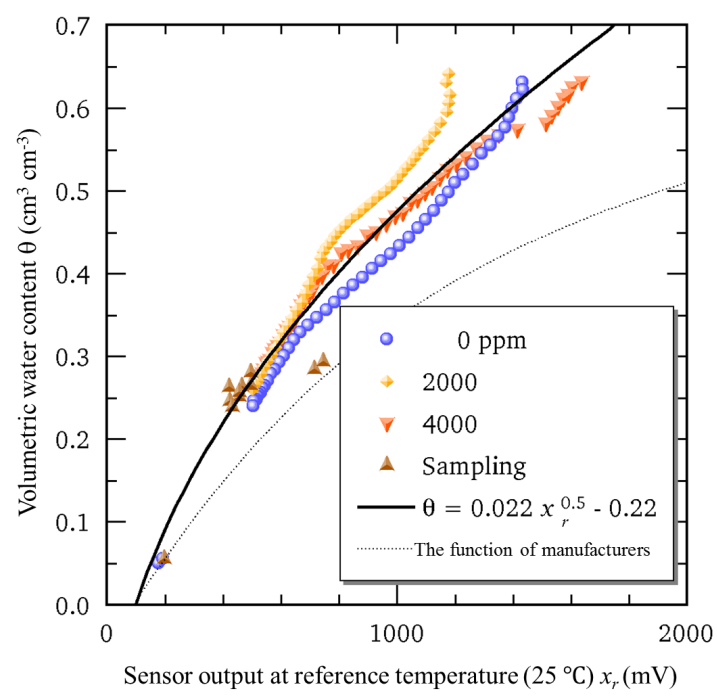

Fig. 5. Calibration function of $5 \mathrm{TE}$ sensor for Kanto loam. $\mathrm{NaCl}$ solutions of $0,2000,4000 \mathrm{ppm}$ were used to calibrate 5TE sensors. Sampling results are the sensor outputs for column A, C, D, E and F. 


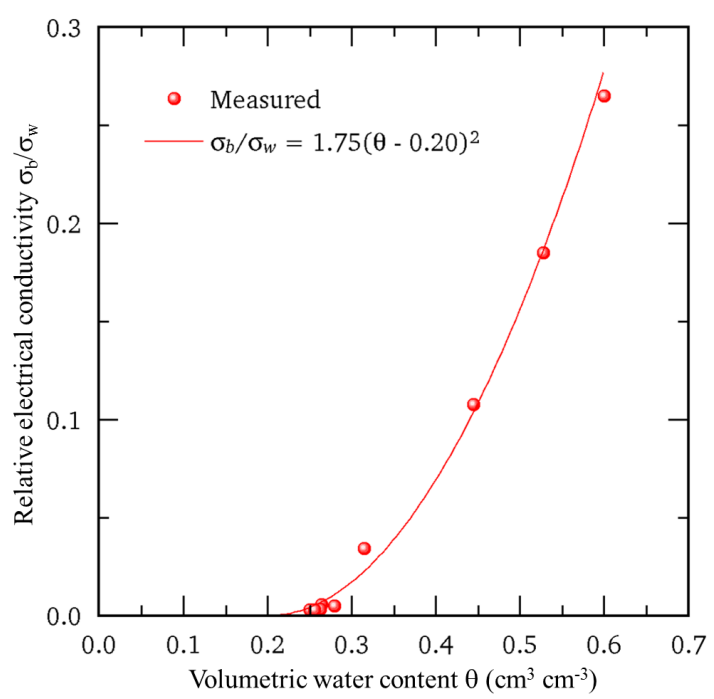

Fig. 6. Dependence of bulk electrical conductivity on volumetric water content measured with 5 TE sensor.

We also measured the dependence of bulk EC $\left(\delta_{b}\right)$ on $\theta$, which is required to calculate the EC of the soil solution $\left(\delta_{w}\right)$ from $\delta_{b}$ and $\theta$ measured with 5TE sensors (Fig. 6):

$$
\frac{\sigma b}{\sigma w}=1.75(\theta-0.20)^{2}
$$

Because EC also depends on temperature, it was normalized to the reference temperature using the following equation (Noborio, 2003):

$\sigma_{w 25}=\sigma_{b} \frac{1+\frac{(298-H)}{49.7}+\frac{(298-H)^{2}}{3728}}{1.75(\theta-0.20)^{2}}$

Concentration of $\mathrm{NaCl}\left(\mathrm{g} \mathrm{kg}^{-1}\right), c$, was calculated with the calibration curve between concentration and $\mathrm{EC}$ of soil solution at reference temperature, $\sigma_{\omega 25}$ :

$\mathrm{c}=0.465 \sigma_{\omega 25}{ }^{1.08}$.

Osmotic head was given by the modified van't Hoff's equation.

$h_{o}=2 \omega \frac{c}{M} x R T$,

where $\omega$ is unit sensing element, $10.2\left(\mathrm{~cm} \mathrm{~kg} \mathrm{~J}^{-1}\right) ; M$ is molecular mass of $\mathrm{NaCl}, 58.5\left(\mathrm{~g} \mathrm{~mol}^{-1}\right) ; x$ is osmotic coefficient; $R$ is gas constant, $8.31\left(\mathrm{~J} \mathrm{~mol}^{-1} \mathrm{~K}^{-1}\right) ; T$ is temperature $(\mathrm{K})$. Then the distribution of osmotic head was estimated by interpolating or extrapolating osmotic heads at the two depths of the soil columns.

\section{Data analysis}

Parameter values in the response function, $h_{50}, h_{050}$ and ${ }_{p}$, were inversely estimated with Levenberg-Marquardt's maxi- mum neighborhood method (Marquardt, 1963). At a given combination of $h_{50}, h_{050}$ and ${ }_{p}$, transpiration rate at each time was calculated using Eqs. (1-5). Potential transpiration rate (Eq. (4)), $T_{p}$, was estimated assuming that the pattern of transpiration is the same as that of the short wave radiation, $R a\left(\mathrm{~W} \mathrm{~m}^{-2}\right)$ (Fujimaki and Kikuchi, 2010):

$$
T_{p}=\tau_{p} \frac{R_{a}}{\int_{0: 00}^{24: 00} R_{a} \mathrm{~d} t}
$$

where $\tau_{p}$ is the potential daily transpiration (cm).

We calculated relative transpiration, $r$, which is the ratio of actual to potential daily transpiration, $\tau$ to $\tau_{p}$, as follow;

$$
r=\frac{\tau}{\tau p}
$$

Daily transpiration was calculated by integrating hourlycalculated transpiration rates, $T_{\text {cal }}\left(\mathrm{cm} \mathrm{s}^{-1}\right)$ :

$\tau \operatorname{cal}(\vec{B})=\int_{0: 00}^{24: 00} T_{c a l}(\vec{B}) d t$,

where $\vec{B}$ is the vector of the optimized parameter. We used root mean square error between actual and calculated daily transpiration, $\tau$ and $\tau_{c a l}$, as the objective function that was to be minimized.

$$
\operatorname{RMSE}(\vec{B})=\left\{\frac{1}{N} \sum_{\tau=1}^{N}\left[\tau_{c a l}(\vec{B})-\tau\right]^{2}\right\}^{0.5} .
$$

\section{RESULTS AND DISCUSSION}

Fig. 7 shows the volumetric water content and EC of soil solution of column A, which was under drought stress. Final application of water was carried out at 2nd March, and then volumetric water content decreased steadily. EC of soil solution was low during drought stress period. Fig. 8 shows the volumetric water content and EC of soil solution of column D, which was under salinity stress. We applied $\mathrm{NaCl}$ solution on 2nd March, and EC of soil solution in the upper layer $(5 \mathrm{~cm}$ depth) increased accordingly. Second irrigation of $\mathrm{NaCl}$ solution on 10th March increased salinity in the lower layer, too. Fig. 9 shows time evolution of the ratio of actual to potential transpiration. Fig. 9 also shows time evolution of average daily transpiration of control columns, $\tau_{\text {ctrl }}\left(\mathrm{mm} \mathrm{d}^{-1}\right)$ and ratio of actual to potential transpiration of the columns. The $\tau_{\text {ctrl }}$ slightly increased even in the growth chamber owing to growth.

Ratio of actual to potential transpiration of column A was decreased after 25th March. Volumetric water content of column A on 25th March was about 0.3 (Fig. 9). Ratio of actual to potential transpiration of column D also decreased immediately after decreasing volumetric water content under 0.3 in 20th March shown in Figs 8 and 9. After optimizing the parameter values for drought stress. We optimized the parameter value for salinity stress. Therefore, high EC of soil solution was evaluated properly. According to Francois (1994), canola was found to have soil salinity threshold values about $10 \mathrm{dS} \mathrm{m}^{-1}$ for vegetation growth. Our results agree with this previous study (around 20th March Figs 10 and 11). 
Fig. 10 shows an example of the profiles on 22nd March 12:00 of column D. Osmotic head was lower at $5 \mathrm{~cm}$ depth while matric head was not low throughout the root zone. In addition to that, normalized root density was higher in deeper area. It seems that low osmotic head at high root density (around $5 \mathrm{~cm}$ depth) hindered root water uptake, resulting in decreased ratio of actual to potential transpiration (at 22nd March in Fig. 10).

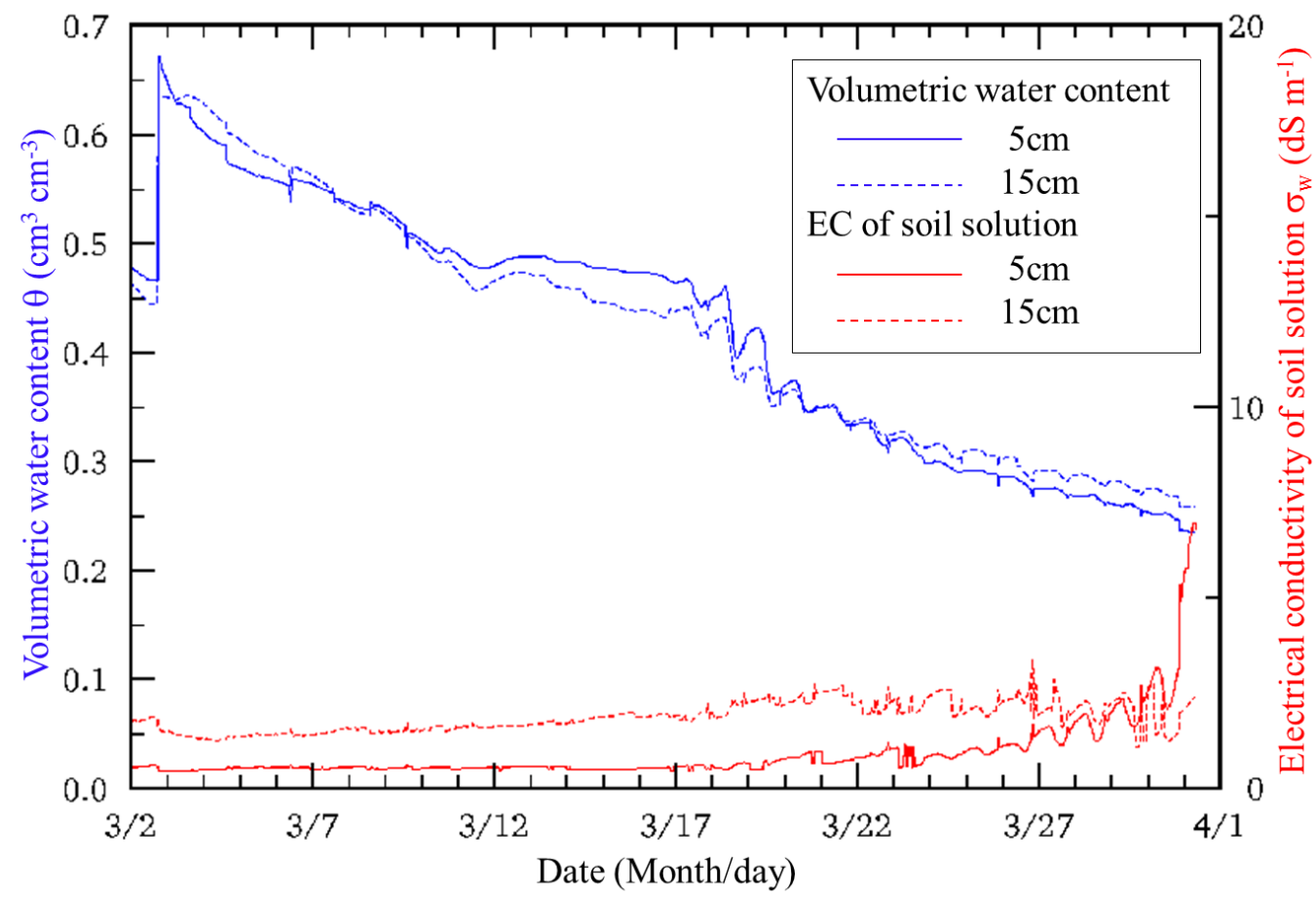

Fig. 7. Variation of soil moisture and electrical conductivity of soil solution at 5 and $15 \mathrm{~cm}$ depth for column A.

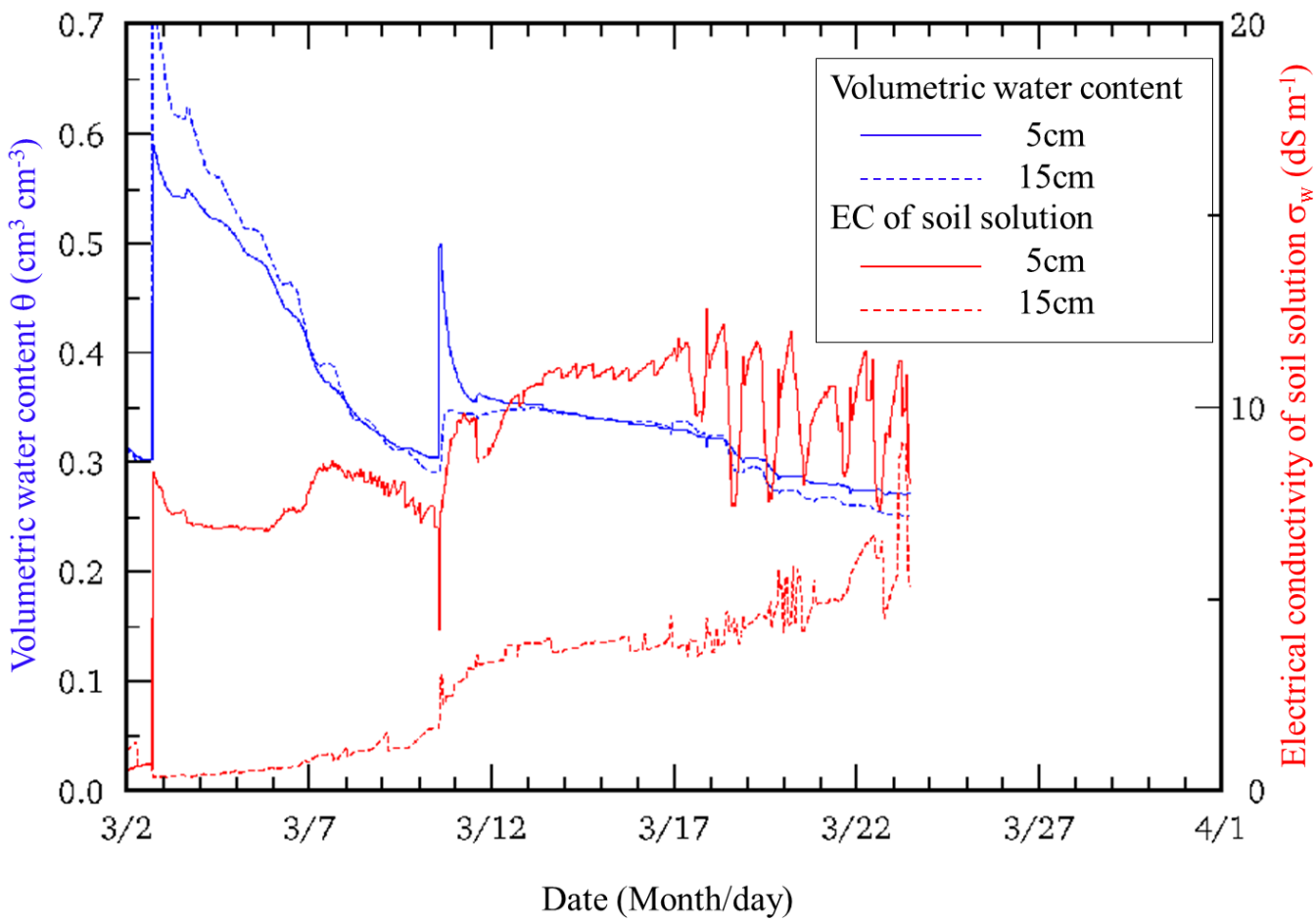

Fig. 8. Validation of soil moisture and electrical conductivity of soil solution at 5 and $15 \mathrm{~cm}$ depth for column D. 


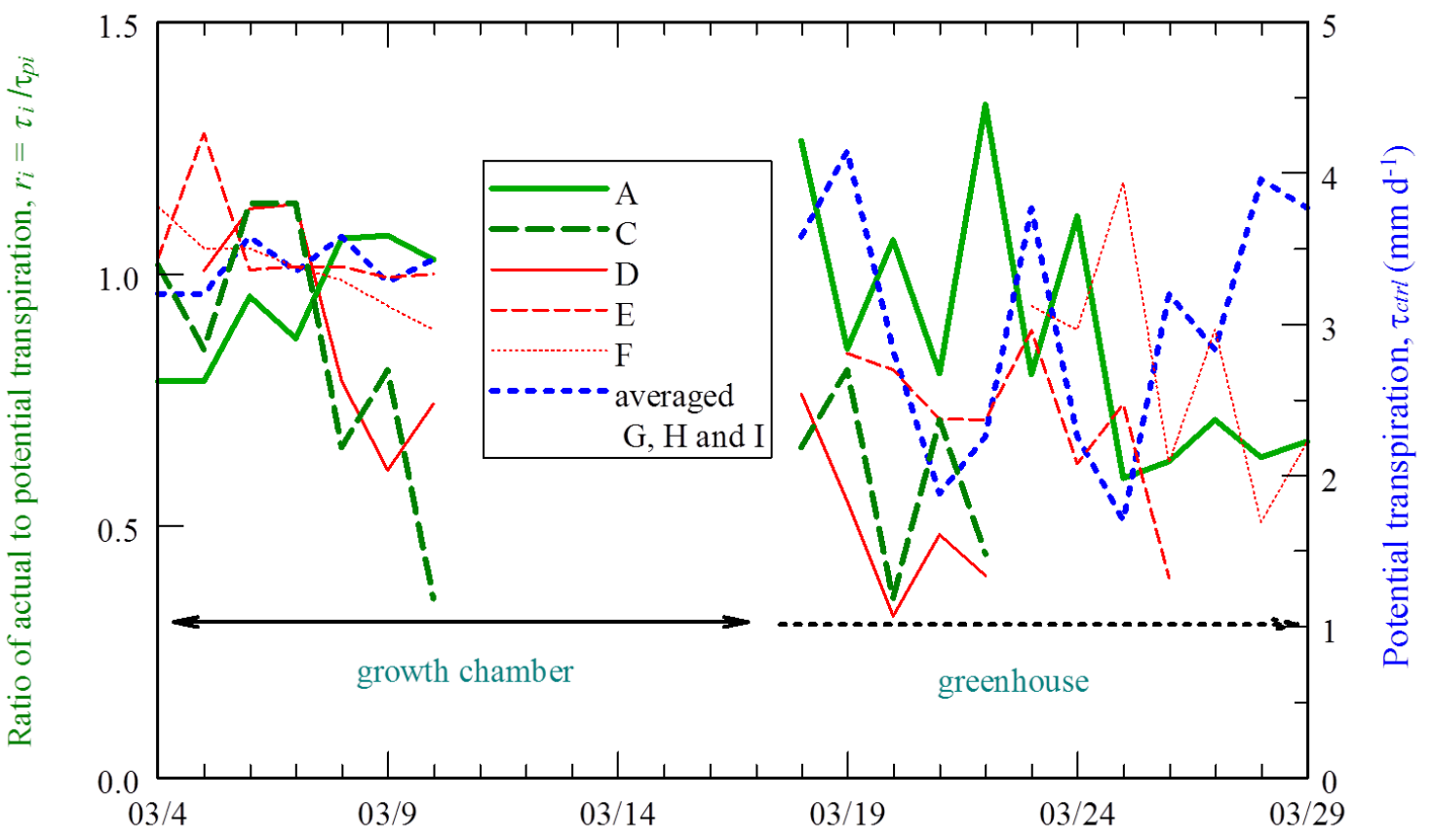

Date (Month/day)

Fig. 9. Daily transpiration ratio and potential transpiration of the experimented columns.

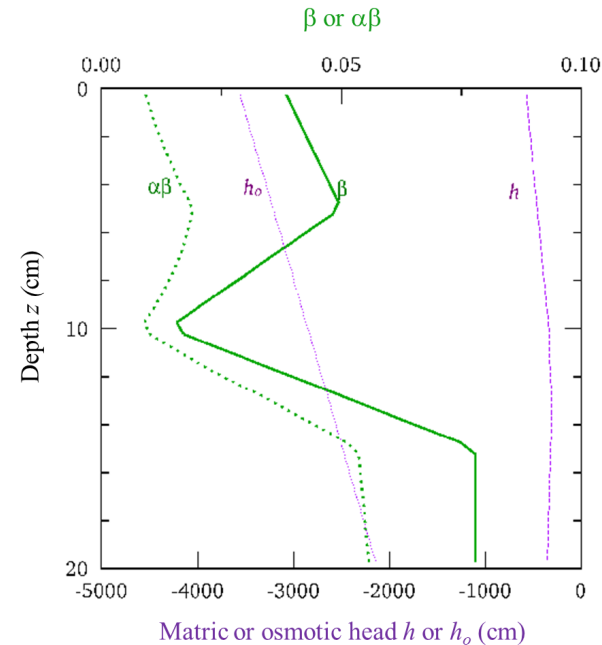

Fig. 10. Examples of root activity $(\beta)$ and reduced root activity $(\alpha \beta)$ profiles on March 22 at 12:00 (column D).

Fig. 11 shows comparison of measured and calculated ratio of actual to potential daily transpiration for column A. Large discrepancy in the ratio occurred for rainy or cloudy days (Fig. 12, 21st, 22nd, and 24th March) when potential transpiration was large and the error caused by individual difference in growth, evaporation loss or error in weighing was exaggerated by the small denominator. Except for these data, calculated values are around the dotted $1: 1$ line, showing good fit, especially under the stress period (27-30th March in Fig. 11).

Fig. 13 shows the optimized stress response functions for A, $\mathrm{C}, \mathrm{D}, \mathrm{E}$ and $\mathrm{F}$ columns. Drought stress response function is drawn by setting osmotic head to zero and a salinity stress response functions is drawn by setting matric head to zero.
Stress functions for Jatropha (Fujimaki and Kikuchi, 2010) are also shown in the same figure to compare tolerances to drought and salinity stresses. Canola was found to be less tolerant to drought stress than Jatropha and as tolerant as Jatropha to salinity stress. At a given value, matric potential is more determining than osmotic potential for root water uptake. Higher absolute value of $h_{050}$ is common among various plants (Feddes and Raats, 2004). It may indicate that the plasma membrane of the root cells is not an ideal semi-permeable membrane, and some ions may intrude into the cells, reducing the difference between the inner and outer osmotic potentials. Table 1 shows parameter values of drought and salinity stresses. Standard deviation of parameter values are around $10 \%$ of the average values.

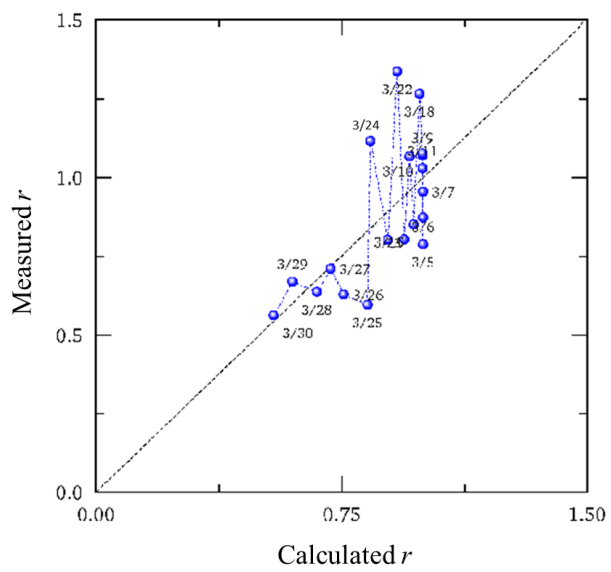

Fig. 11. Comparison of measured and calculated ratio of actual to potential daily transpiration (column A) on different days (month/day). 
As mentioned in introduction, canola is a candidate as a biofuel crop. Results of present study show that canola can be cultivated with saline water irrigation. In arid and semi-arid region, EC of irrigation water is increased with salts especially in downstream area. According to Rhoades et al. (1999), EC of soil solution $\left(\mathrm{dS} \mathrm{m} \mathrm{m}^{-1}\right)$ at $25^{\circ} \mathrm{C}$ can be converted to osmotic potential (MPa) using the following equation:

$h_{o} \approx 0.04 \sigma_{w}$,

where $\sigma_{\mathrm{w}}$ is the EC of the soil solution. Average value of $h_{o 50}$ was $-4395 \mathrm{~cm}$ in present study. $-4395 \mathrm{~cm}(-431 \mathrm{kPa})$ can be converted to $10.8 \mathrm{dS} \mathrm{m}^{-1}$ of EC of soil solution. According to FAO data on irrigation water quality (Ayers and Westcot, 1985), EC of soil solution is approximately 3.2 times more concentrated than the applied irrigation water. The $10.8 \mathrm{dS} \mathrm{m}^{-1}$ EC of soil solution could be resulted by irrigation with $3.4 \mathrm{dS}$ $\mathrm{m}^{-1}$. If reduction coefficient is proportional to relative yield (ratio of actual to potential yield), a crop with 0.5 relative yield at $3.4 \mathrm{dSm}^{-1}$ of EC of irrigation water is classified as "moderately sensitive" in widely-used guidelines of water quality for irrigation (Ayers and Westcot, 1985). On the other hand, since drought stress affects canola more seriously, more frequent irrigation is required for this plant.

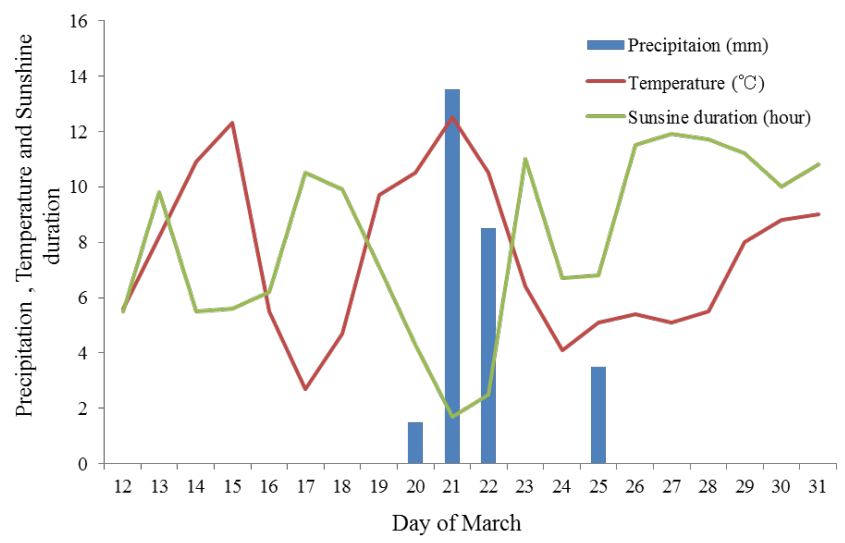

Fig. 12. Precipitation, average temperature and sunshine duration during the green house experiment.

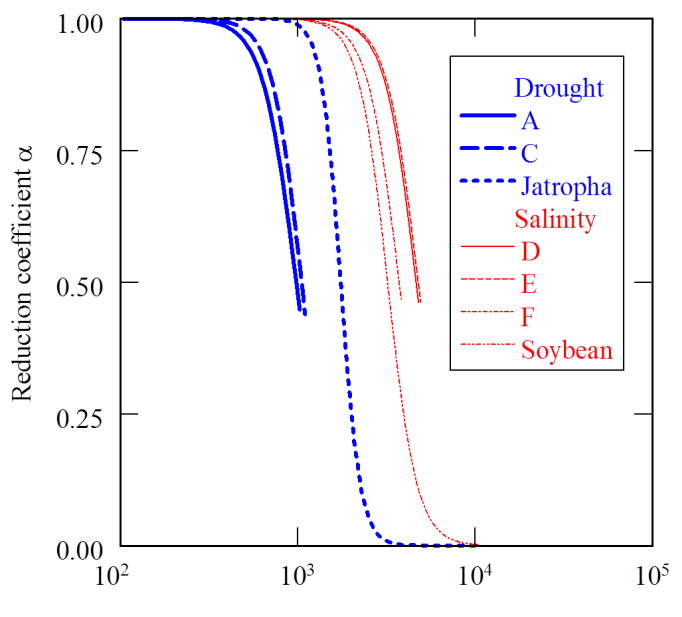

Matric or osmotic head $h, h_{0}(-\mathrm{cm})$

Fig. 13. Drought and salinity stress response functions for canola and Jatropha. Data for Jatropha are from Fujimaki and Kikuchi (2010).

\section{SUMMARY AND CONCLUSION}

We estimated parameter values for drought and salinity stress function of canola with a widely used macroscopic root water uptake algorithm. Parameter values, $h_{50}, h_{o 50}$ and ${ }_{p}$, were inversely determined by minimizing the sum of square difference measured and calculated daily transpiration rates. Water uptake at each depth and time was calculated by substituting linearly interpolated osmotic potential into the stress response function.

Results indicate that canola is as tolerant as Jatropha for salinity stress. Canola was also found to be less tolerant to drought stress than Jatropha. At the same value, matric potential was more critical than osmotic potential to root water uptake. Frequent irrigation would be essential for canola in arid and semi-arid regions. Canola may be cultivated as a biofuel crop in arid and semi-arid regions using moderately saline irrigation water.

Table 1. Parameter value for drought and salinity stresses.

\begin{tabular}{lcccccc}
\hline & \multicolumn{2}{c}{ Drought stress } & & \multicolumn{3}{c}{ Salinity stress } \\
\cline { 2 - 3 } \cline { 5 - 7 } & $\mathrm{A}$ & $\mathrm{C}$ & & $\mathrm{D}$ & $\mathrm{E}$ & $\mathrm{F}$ \\
\hline$h_{50}$ & 983 & 1055 & & & & \\
$h_{050}$ & & & & 4659 & 4791 & 3736 \\
$p$ & 4.6 & 5.2 & & 4.9 & 4.9 & 4.9 \\
\hline Averaged & & & & & \\
$h_{50}$ or $h_{050}$ & 1019 & & & 4395.3 & \\
S.D. & 50.9 & & & 574.8 & \\
Averaged & 4.9 & & & 4.9 & \\
S.D. & 0.4 & & & 0 & \\
\hline
\end{tabular}

S.D.: Standard deviation. Since we estimated and optimized the parameter values for drought stress at first, $p$ value of salinity stress is the same as averaged. Then we optimized the parameter value $\left(h_{o 50}\right)$ for salinity stress.

Acknowledgements. This study was carried out under the science and technology research partnership for sustainable development (satreps) project, sustainable systems for food and bioenergy production with water-saving irrigation in the Egyptian Nile basin', with additional support from JSPS grant-in-aid for JSPS fellows to A. Yanagawa (FY2012-2015, No.24-7604).

\section{REFERENCES}

Ahmadi, S., Ardekani, J., 2006. The effect of water salinity on growth and physiological stages of eight Canola (Brassica napus) cultivars. Irrigation Science, 25, 1, 11-20.

Ashraf, M., McNeilly, T., 1990. Responses of four Brassica species to sodium chloride. Environmental and Experimental Botany, 30, 4, 475-487.

Ayers, R.S., Westcot, D.W., 1985. Water Quality for Agriculture. Food and Agriculture Organization of the United Nations, Rome.

Feddes, R.A., Kowalic, P.J., Zaradny, H., 1978. Simulation of Field Water Use and Crop Yield. John Wiley \& Sons, New York.

Feddes, R.A., Raats, P.A.C., 2004. Parameterizing the soilwater-plant root system. In: Feddes, R.A., et al. (Eds.), Unsaturated-zone modeling: Progress, challenges and applications. Wageningen UR Frontis Series. Kluwer Academic Publishers, Dordrecht, The Netherlands, 95-141. 
Francois, L.E., 1994. Growth, seed yield, and oil content of canola grown under saline conditions. Agronomy Journal, 86, 2, 233-237.

Fujimaki, H., Kikuchi, N., 2010. Drought and salinity tolerances of young Jatropha. International Agrophysics, 24, 2, 121-127 .

Homaee, M., Feddes, R.A., Dirksen, C., 2002. A Macroscopic Water Extraction Model for Nonuniform Transient Salinity and Water Stress. Soil Science Society of America Journal, 66, 6, 1764-1772.

Huang, J., Redmann, R., 1995. Physiological responses of canola and weld mustard to salinity and contrasting calcium supply. Journal of Plant Nutrition, 18, 9, 1931-1949.

Huzsvai, L., Rajkai K., 2009. Modeling of plant adaptation to climatic drought induced water deficit. Biologia, 64, 536-540 .

Johnson, B., McKay, K., Schneiter, A., Hanson, B., Schatz, B., 1995. Influence of planting date on canola and crambe production. Journal of Production Agriculture, 8, 4, 594-598.

Kool, J., Parker, J., 1987. Development and evaluation of closed-form expressions for hysteretic soil hydraulic properties. Water Resources Research, 23, 1, 105-114.

Marquardt, D.W., 1963. An algorithm for least-squares estimation of nonlinear parameters. Journal of the Society for Industrial and Applied Mathematics, 11, 2, 431-441.

Newman, E., 1966. A method of estimating the total length of root in a sample. Journal of Applied Ecology, 139-145.

Nielsen, D.C., 1997. Water use and yield of canola under dryland. J. Prod. Agric, 10, 2, 213.

Nimah, M., Hanks, R., 1973. Model for estimating soil water, plant, and atmospheric interrelations: I. Description and sensitivity. Soil Science Society of America Journal, 37, 4, $522-527$.
Noborio, K., 2003. Practical application of time domain reflectometry: Simultaneous measurement of water and salt contents in soil. J. Jpn. Soc. Soil Phys., 93, 57-65.

Redmann, R., Qi, M., Belyk, M., 1994. Growth of transgenic and standard canola (Brassica napus L.) varieties in response to soil salinity. Canadian Journal of Plant Science, 74, 4, 797-799.

Rhoades, J.D., Chanduvi, F., Lesch, S.M., 1999. Soil Salinity Assesment: Methods and Interpretation of Electrical Conductivity Measurements. FAO Irrigation and Drainage Paper 57. Food and Agriculture Organization of the United Nations, Rome, 1-150.

Šimůnek, J., Genuchten, M.T.v., Šejna., M., 2006. The HYDRUS software package for simulating the two- and threedimensional movement of water, heat, and multiple solutes in variably-saturated media. PC Progress, Prague, Czech Republic.

Twarakavi, N.K.C., Saito, H., Šimůnek, J., van Genuchten, M.T., 2010. Inverse modeling of vadose zone flow processes using squared $\varepsilon$-insensitivity loss function. J. Hydrol. Hydromech., 58, 3, 188-200.

Van Dam, J.C. et al., 1997. Theory of SWAP, version 2.0: Simulation of water flow, solute transport and plant growth in the soil-water-atmosphere-plant environment. Rep. no. 71, pp. Dep. of Water Resour., Wageningen Agricultural Univ., Wageningen, The Netherlands.

Van Genuchten, M.T., 1987. A numerical model for water and solute movement in and below the root zone. U.S. Salinity Laboratory. USDA- ARS, Riverside, CA.

Received 2 November 2012 Accepted 15 January 2013 